\title{
Outcomes in Patients with COVID-19 Infection Taking ACEI/ARB
}

\author{
Juan Simon Rico-Mesa ${ }^{1} \cdot$ Averi White $^{1} \cdot$ Allen S. Anderson $^{2}$ \\ Published online: 14 April 2020 \\ (C) Springer Science+Business Media, LLC, part of Springer Nature 2020
}

\begin{abstract}
Purpose of Review Severe acute respiratory syndrome coronavirus 2 (SARS-CoV-2) is the virus responsible for the aggressive coronavirus disease (COVID-19) pandemic. Recently, investigators have stipulated that COVID-19 patients receiving angiotensin-converting-enzyme inhibitors (ACEI) may be subject to poorer outcomes. This editorial presents the available evidence to guide treatment practices during this pandemic.

Recent Findings Recent studies from Wuhan cohorts provide valuable information about COVID-19. A cohort with 52 critically ill patients revealed cardiac injury in $12 \%$ of patients. Worse outcomes appear to be more prevalent in patients with hypertension and diabetes mellitus (DM), possibly due to overexpression of angiotensin-converting enzyme 2 (ACE2) receptor in airway alveolar epithelial cells. Investigators suspect that SARS-CoV-2 uses the ACE2 receptor to enter the lungs in a mechanism similar to SARS-CoV. Several hypotheses have been proposed to date regarding the net effect of ACEI/ARB on COVID-19 infections. Positive effects include ACE2 receptor blockade, disabling viral entry into the heart and lungs, and an overall decrease in inflammation secondary to ACEI/ARB. Negative effects include a possible retrograde feedback mechanism, by which ACE2 receptors are upregulated.

Summary Even though physiological models of SARS-CoV infection show a theoretical benefit of ACEI/ARB, these findings cannot be extrapolated to SARS-CoV-2 causing COVID-19. Major cardiology scientific associations, including ACC, HFSA, AHA, and ESC Hypertension Council, have rejected these correlation hypotheses. After an extensive literature review, we conclude that there is no significant evidence to support an association for now, but given the rapid evolvement of this pandemic, findings may change.
\end{abstract}

Keywords COVID-19 $\cdot$ SARS-COV $2 \cdot$ ACEI $\cdot$ ARB $\cdot$ ACE2 receptor

\section{Introduction}

Severe acute respiratory syndrome coronavirus 2 (SARSCoV-2) is the virus responsible for COVID-19, a global pandemic with catastrophic consequences for healthcare systems

Juan Simon Rico-Mesa and Averi White share first authorship

Allen S. Anderson

Andersona4@uthscsa.edu

Juan Simon Rico-Mesa

mesajs@uthscsa.edu

Averi White

whitea4@livemail.uthscsa.edu

1 Department of Medicine, University of Texas Health San Antonio, San Antonio, TX 78229, USA

2 Department of Medicine, Division of Cardiovascular Diseases, University of Texas Health San Antonio, 7703 Floyd Curl Drive, MC 7872, San Antonio, TX 78229, USA and populations around the world. SARS-CoV-2 was initially described in December 2019 in Wuhan, China [1]. The virus rapidly escalated and on March 11, 2020; the World Health Organization declared it a pandemic. SARS-CoV-2 shares similarities with SARS-CoV, the virus responsible for the 2002-2003 SARS epidemic, and Middle Eastern respiratory syndrome coronavirus (MERS), the virus responsible for MERS [2]. Following the SARS epidemic, researchers extensively investigated the pathophysiologic mechanisms of SARS-CoV infection, including the interaction of the virus with the heart and lungs. Based on these studies, researchers believe that the angiotensin-converting enzyme 2 (ACE2) receptor, located on alveolar epithelial cells, serves as a high affinity receptor and co-transporter for SARS-CoV-2 to enter the lungs [3]. Medications, such as angiotensin-converting enzyme inhibitors (ACEI), block ACE2 receptors, which may predispose or protect against COVID-19 infection. This editorial summarizes the current scientific evidence surrounding this subject in order to guide clinical practice. 


\section{Background}

The renin-angiotensin-aldosterone system (RAAS) maintains plasma sodium concentration via feedback from blood pressure, baroreceptors, and sodium and potassium levels. First, the kidneys secrete renin, which metabolizes angiotensinogen into angiotensin I. Next, the kidneys and lungs secrete ACE, which converts angiotensin I into angiotensin II. Finally, angiotensin II stimulates vasoconstriction, cardiovascular response, and aldosterone and ADH production; this ultimately increases blood pressure and body fluid volume through sodium, potassium, and free water resorption [3]. ACE2 receptor, a homolog of the angiotensin I-converting enzyme (ACE) receptor, is a type I transmembrane aminopeptidase with high expression in heart and lung tissue [4], but which is also expressed in the endothelium and kidney (see Fig. 1, illustrating the RAAS activation pathway). Discovered in 2000, ACE2 receptor appears to counter-regulate RAAS activation by degrading angiotensin II [5]. The RAAS system is widely implicated in DM, hypertension, and heart failure. ACEI and ARB drugs, based upon strong evidence of efficacy, are commonly used in the management of hypertension, heart failure, post myocardial infarction care, and to slow progression of renal disease associated with diabetes.

\section{COVID-19 and Comorbidity}

With the exponential rise of COVID-19 cases worldwide, observational studies have identified risk factors for infection and poor outcomes. Three separate studies identified hypertension and DM as highly prevalent among COVID-19 patients:
A. According to Yang et al., among 52 critically ill patients, DM was present in $17 \%$ of cases [6].

B. According to Guan et al., among 1099 patients, DM was present in $16.2 \%$ of cases and hypertension was present in $23.7 \%$ of cases [7].

C. According to Zhang et al., among 140 hospitalized patients, DM was present in $12 \%$ of cases and hypertension was present in $30 \%$ of cases [8].

While both hypertension and DM are treated with ACEI and $\mathrm{ARB}$, medication use was not assessed in any of the three aforementioned studies, leading to an inconclusive hypothesis. However, one study to date has analyzed the effect of ACEI and ARB use on the COVID-19 population. According to Peng et al., among 112 patients, cardiovascular comorbidities led to worse outcomes, with most deaths occurring secondary to fulminant inflammation, lactic acidosis, and thrombotic states [9]. ACEI and ARB use did not influence morbidity or mortality [9].

In addition to these observations, there is a well-known association between the viruses, SARS-CoV and MERS$\mathrm{CoV}$, and deleterious cardiac events, including cardiac injury in SARS-CoV as well as myocarditis and heart failure in MERS-CoV [10]. Furthermore, SARS-CoV-2 was recently associated with cardiac injury, defined by a troponin $>$ $28 \mathrm{pg} / \mathrm{ml}$ or electrocardiogram/echocardiogram abnormalities, in $12 \%$ of patients from a COVID-19 cohort. These data demonstrate a cardiac affinity with all three viruses [11].

\section{Pros and Cons of ACE Inhibition}

The etiology of cardiac damage in patients with COVID-19 is unclear, but ACE2 receptors may play a role, given the high affinity of SARS-CoV for ACE2 receptors [12]. A recent

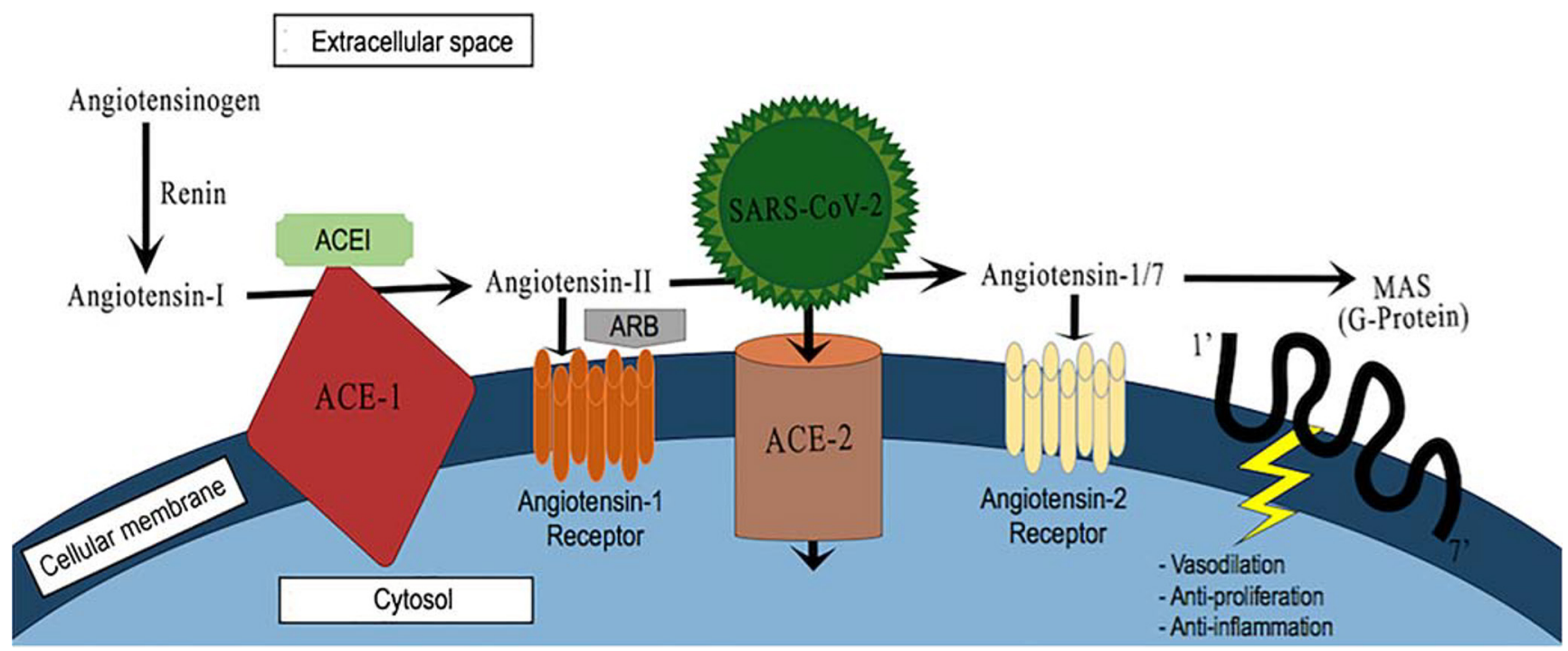

Fig. 1 RAAS pathway showing ACEI/ARB mechanism of action and SARS and SARS-COV2 infectious mechanism via ACE2 receptors 
commentary published in the Lancet Respiratory Medicine hypothesizes that the use of ACE2 receptor increasing drugs is at higher risk for severe COVID-19 infection. ACEI initially inhibits ACE leading to decreased angiotensin I levels, causing a possible negative feedback loop that ultimately upregulates more ACE2 receptor to be able to interact with the decreased angiotensin I substrate available [13] (see Fig. 1.). This ACE2 receptor upregulation results in increased binding sites for SARS-CoV-2, leading to preferential COVID-19 infection. This is particularly observed in patients with diabetes and/or hypertension, since they are usually taking ACEI or ARB [12]. This comment was released before the findings published by Peng et al. [9]. An editorial response by Sommerstein et al. [14], based on the findings by Ferrario et al. showing a 5-fold increase in ACE2 levels with lisinopril and 3-fold increase in ACE2 levels with losartan [15], was published in the British Medical Journal.

Conversely, some investigators argue that ACEI or ARB use may be beneficial in COVID-19 infection prevention. Li et al., for example, proposed that ACEI inhibition of ACE may stimulate a negative feedback (given the lack of angiotensin II, upregulating ACE2 receptors and decreasing overall inflammation [16]). Sun et al. argued that ACEI use im pairs the $\mathrm{ACE} /$ angiotensin II/angiotensin-1 receptor pathway, therefore, impairing the integrity of the ACE2/angiotensin 1-7/ MAS (MAS-related G protein-coupled receptor). A disruption of the ACE2/angiotensin 1-7/MAS pathway could lead to decreased production of ACE2, decreasing chances of SARS-CoV-2 entering the cell [17]. Some RAAS inactivated animal models demonstrate symptom relief in acute severe pneumonia and respiratory failure, through vasoconstriction mechanisms [17]. Recent findings also demonstrate that patients on the ARB olmesartan had increased secretion of urinary ACE2, likely from an upregulation mechanism, although unclear [18]. Despite this hypothesis of ACE2 upregulation, a causal relationship decreasing mortality has not been demonstrated.

Finally, given the contradictory hypotheses, rapidly evolving nature of the disease, and social media-related hysteria, several cardiology associations (HFSA/ACC/AHA and ESC Hypertension Council) released an official statement regarding the continuation of ACEI and ARB for COVID-19 patients [19]. The associations strongly recommend continuing treatment with ACEI/ARB in patients who were previously taking either class of medication.

\section{Conclusions}

There is a lack of scientific evidence and clinical data to support discontinuing ACE/ARB use in patients with COVID-19 and co-existing heart failure, hypertension, or ischemic heart disease. The well-studied reduction in mortality conferred by
ACE/ARB use and the beneficial effects for patients with diabetes, chronic kidney disease, and proteinuria or albuminuria currently outweigh the theoretical risks. As the COVID19 pandemic continues to rapidly evolve and affect more patients with cardiovascular comorbidities, further research is needed to clarify the accuracy of existing hypotheses.

\section{Compliance with Ethical Standards}

Conflict of Interest Dr. Rico-Mesa and Ms. White have nothing to disclose. Dr. Anderson has received honoraria from Novartis, Pfizer. He is a consultant for Edwards LifeSciences and received research support from Abbott.

Human and Animal Rights and Informed Consent This manuscript does not contain any studies with human or animal subjects.

\section{References}

1. Wu Z, McGoogan JM. Characteristics of and important lessons from the coronavirus disease 2019 (COVID19) outbreak in China: summary of a report of 72314 cases from the Chinese Center for Disease Control and Prevention. [published online ahead of print (February 24, 2020)]. JAMA. 2020.

2. Liu J, Zheng X, Tong Q, Li W, Wang B, Sutter K, Trilling M., Lu M., Dittmer U., Yang D. Overlapping and discrete aspects of the pathology and pathogenesis of the emerging human pathogenic coronaviruses SARSCoV, MERS-CoV, and 2019- nCoV. J Med Virol. 2020;92(5):491-4.

3. Sparks MA, Crowley SD, Gurley SB, Mirotsou M, Coffman TM. Classical renin- angiotensin system in kidney physiology. Compr Physiol. 2014;4(3):1201-28.

4. Velavan TP, Meyer CG. The COVID-19 epidemic. Tropical Med Int Health. 2020;25(3):278-80.

5. Kuba K, Imai Y, Ohto-Nakanishi T, Penninger JM. Trilogy of ACE2: a peptidase in the renin- angiotensin system, a SARS receptor, and a partner for amino acid transporters. Pharmacol Ther. 2010;128(1):119-28.

6. Yang X, Yu Y, Xu J, Shu H, Xia J, Liu H, Wu Y, Zhang L, Yu Z, Fang M, Yu T, Wang Y, Pan S, Zou X, Yuan S. Clinical course and outcomes of critically ill patients with SARS-CoV-2 pneumonia in Wuhan, China: a single-centered, retrospective, observational study. [published online ahead of print (February 24, 2020)]. Lancet Respir Med. 2020.

7. Guan WJ, Ni ZY, Hu Y, Liang WH, Ou CQ, He JX, Liu L, Shan H, Lei CL, Hui DS, Du B, Li LJ, eng G, Yuen KY, Chen R, Tang CL, Wang T, Chen PY, Xiang J, Li SY, Wang JL, Liang ZJ, Peng YX, Wei L, Liu Y, Hu YH, Peng P, Wang JM, Liu JY, Chen Z, Li G, Zheng ZJ, Qiu SQ, Luo J, Ye CJ, Zhu SY, Z NS. Clinical characteristics of coronavirus disease 2019 in China. [published online ahead of print (February 28, 2020)]. N Engl J Med. 2020.

8. Zhang JJ, Dong X, Cao YY, Yuan YD, Yang YB, Yan YQ, Akdis CA, Gao YD. Clinical characteristics of 140 patients infected with SARS-CoV-2 in Wuhan, China. [published online ahead of print (February 19, 2020)]. Allergy. 2020.

9. Peng YD, Meng K, Guan HQ, Leng L, Zhu RR, Wang BY, He MA, Cheng LX, Huang K, Zeng QT. Clinical characteristics and outcomes of 112 cardiovascular disease patients infected by 2019nCoV. [published online ahead of print (March 2, 2020)]. Zhonghua Xin Xue Guan Bing Za Zhi. 2020;48(0):E004. 
10. Alhogbani T. Acute myocarditis associated with novel Middle East respiratory syndrome coronavirus. Ann Saudi Med. 2016;36(1):7880.

11. Huang C, Wang Y, Li X, Ren L, Zhao J, Hu Y, Zhang L, Fan G, Xu J, Gu X, Cheng Z, Yu T, Xia J, Wei Y, Wu W, Xie X, Yin W, Li H, Liu M, Xiao Y, Gao H, Guo L, Xie J, Wang G, Jiang R, Gao Z, Jin Q, Wang J, Cao B. Clinical features of patients infected with 2019 novel coronavirus in Wuhan, China. Lancet. 2020;395(10223): 497-506.

12. Fang L, Karakiulakis G, Roth M. Are patients with hypertension and diabetes mellitus at increased risk for COVID-19 infection? Lancet Respir Med. 2020;8(4):PE21.

13. Nahum LH. The renin angiotensin-aldosterone system (RAAS) in normal man. Conn Med. 1965;29(10):710-1.

14. Watkins J. Preventing a covid-19 pandemic. BMJ. 2020;368:m810.

15. Ferrario CM, Jessup J, Chappell MC, Averill DB, Brosnihan KB, Tallant EA, Diz DI, Gallagher PE. Effect of angiotensin-converting enzyme inhibition and angiotensin II receptor blockers on cardiac angiotensinconverting enzyme 2. Circulation. 2005;111(20):260510 .
16. Li XC, Zhang J, Zhuo JL. The vasoprotective axes of the reninangiotensin system: physiological relevance and therapeutic implications in cardiovascular, hypertensive and kidney diseases. Pharmacol Res. 2017;125(Pt A):21-38.

17. Sun ML, Yang JM, Sun YP, Su GH. Inhibitors of RAS might be a good choice for the therapy of COVID-19 pneumonia. Zhonghua Jie He He Hu Xi Za Zhi. 2020;43(3):219-22.

18. Furuhashi M, Moniwa N, Mita T, Fuseya T, Ishimura S, Ohno K, Shibata S., Tanaka M., Watanabe Y, Akasaka H, Ohnishi H, Yoshida H, Takizawa H, Saitoh S, Ura N, Shimamoto K, Miura T. Urinary angiotensinconverting enzyme 2 in hypertensive patients may be increased by olmesartan, an angiotensin II receptor blocker. Am J Hypertens. 2015;28(1):15-21.

19. Patients taking ACE-i and ARBs who contract COVID-19 should continue treatment, unless otherwise advised by their physician [press release]. heart.org, March 17, 20202020.

Publisher's Note Springer Nature remains neutral with regard to jurisdictional claims in published maps and institutional affiliations. 